\title{
Progressive age and other factors affecting scoliosis severity in cerebral palsy patients
}

\author{
Ryoko Takeuchi ${ }^{1}$, Hirotaka Mutsuzaki ${ }^{1}$, Yuki Mataki $^{1}$, and Hiroshi Kamada ${ }^{2}$ \\ ${ }^{1}$ Department of Orthopedic Surgery, Ibaraki Prefectural University of Health Sciences, Japan \\ ${ }^{2}$ Department of Orthopedic Surgery, University of Tsukuba, Japan
}

\begin{abstract}
Objective: This study aimed to investigate the age at which scoliosis progresses to a severe condition and identify the factors related to severe scoliosis in patients with cerebral palsy.

Patients and Methods: This retrospective study included 51 patients aged $\geq 15$ years. The Cobb angle was measured over time using radiographs. Patients were divided into the following groups according to their final Cobb angle: $<60^{\circ}, 60^{\circ}-100^{\circ}$, and $\geq 100^{\circ}$. The age at which the Cobb angle was $\geq 20^{\circ}$ in the patients was compared among the groups. Moreover, the age at which a significant difference in the Cobb angle occurred in the groups was considered the age at which the scoliosis worsened. Association of the final Cobb angle with factors such as the location of curve, Gross Motor Functional Classification System (GMFCS), capability of turning over, orthosis use, hip dislocation, tracheotomy, and gastric fistula was examined.

Results: The mean age at which the Cobb angle was $\geq 20^{\circ}$ was significantly lower in the $\geq 100^{\circ}$ group. From 9 years of age, a significant difference was noted in the Cobb angle between the $<60^{\circ}$ group and $\geq 100^{\circ}$ group. Between $13-19$ years, a significant difference in the Cobb angle was observed among the three groups. Furthermore, GMFCS, capability of turning over, hip dislocation, and gastric fistula were the factors showing a significant difference among the three groups.

Conclusion: Scoliosis progressed to the severe form $\left(\mathrm{Cobb}\right.$ angle $\geq 100^{\circ}$ ) at 9 years of age. Moreover, scoliosis is aggravated during the growth period. Severe cerebral palsy with low motor function levels and problems with internal functions was considered the cause of scoliosis deterioration.
\end{abstract}

Key words: cerebral palsy, scoliosis, Cobb angle

(J Rural Med 2020; 15(4): 164-169)

\section{Introduction}

Scoliosis is the most common complication occurring in patients with cerebral palsy (CP), with an incidence of $21-68 \%{ }^{1-3)}$. Asymmetric spasticity and the effect of gravity are considered as factors related to the development of scoliosis in patients with $\mathrm{CP}^{2,4)}$. Surgical interventions may be considered for progressive scoliosis in patients with $\mathrm{CP}$, in which curve progression could cause loss of ambulation,

Received: March 31, 2020

Accepted: May 7, 2020

Correspondence: Ryoko Takeuchi, Department of Orthopedic Surgery, Ibaraki Prefectural University of Health Sciences, 4669-2 Ami, Ami-machi, Inashiki-gun, Ibaraki 300-0394, Japan E-mail: a_boor88@yahoo.co.jp

This is an open-access article distributed under the terms of the Creative Commons Attribution Non-Commercial No Derivatives (by-nc-nd) License $<\mathrm{http}: / /$ creativecommons.org/ licenses/by-nc-nd/4.0/> decreased sitting tolerance, or pain ${ }^{5}$. Furthermore, severe scoliosis can cause ventilation dysfunction ${ }^{6}$ ) and gastrointestinal disorders. Therefore, severe scoliosis could worsen the general condition of patients with $\mathrm{CP}$.

In order to plan the prevention and treatment strategy for scoliosis in patients with CP effectively, it is necessary to know the natural course of scoliosis. Therefore, this study aimed to determine the age at which the condition progresses to severe scoliosis and identify factors related to severe scoliosis in patients with CP.

\section{Patients and Methods}

The ethics committee of Ibaraki Prefectural University of Health Sciences reviewed and approved this retrospective study (approval number: e88). We adopted an opt-out style to maintain the rights of the patients to end their participation in the study whenever they desired.

This retrospective study included patients with $\mathrm{CP}$, aged $\geq 15$ years, who exhibited a Cobb angle of $\geq 20^{\circ}$ as of 2018 . 
All participants included were patients at our hospital. Patients who had undergone scoliosis surgery were excluded, but those who received orthotic treatment were included. Full spinal radiographs of all patients were reviewed.

The severity of the scoliosis was measured using the Cobb method based on supine whole-spine radiographs. Moreover, we examined the type of curve (single, double), location of the apex vertebra (thoracic T1-T11, thoracolumbar T12-L1, and lumbar L2-L4), and convex side (left and right). In cases with a double curve, the major curve was measured.

The patients were divided into the following groups according to the Cobb angle during the final follow-up: $<60^{\circ}$ group, $60^{\circ}-100^{\circ}$ group, and $\geq 100^{\circ}$ group. The age at which the patients in the three groups were diagnosed with a Cobb angle of $\geq 20^{\circ}$ was compared. Furthermore, the age at which a significant difference in the Cobb angle occurred in the three groups was considered the age at which the scoliosis worsened.

Factors related to the severity of scoliosis were also examined. The association between the Cobb angle at the final follow-up and each factor was investigated. The factors expected to be associated with scoliosis were location of the curve (thoracic, thoracic lumbar, lumbar), Gross Motor Functional Classification System (GMFCS), capability of turning over, use of orthosis, presence/absence of hip dislocation, presence/absence of tracheotomy, and presence/ absence of gastric fistula. The GMFCS comprises of levels I-V. Capability of turning over was defined as the ability to turn from the supine position to the lateral position, from the lateral position to the prone position, from the prone position to the lateral position, etc. Hip dislocation was defined as a migration percentage of $\geq 100 \%$ as measured on the radiographs.

\section{Statistical analysis}

For the factors related to the severity of scoliosis, the comparison of data between two groups was analyzed using the Mann-Whitney test, whereas comparison of data among the three groups was performed using the Kruskal-Wallis test. When the results were significantly different, they were examined using Bonferroni correction to determine the dif- ference among the groups. All statistical analyses were performed using the Statistical package for the Social Sciences software version 25 (SPSS Inc., Chicago, Illinois, USA). A significance level of $5 \%$ was chosen for all tests $(P<0.05)$.

\section{Results}

A total of 51 patients ( 33 male and 18 female) were included in the analysis. Regarding the type of $\mathrm{CP}, 42$ patients were diagnosed with spastic $\mathrm{CP}, 7$ with dyskinetic $\mathrm{CP}$, and 2 with hypotonic CP. In terms of the classification of the paralysis, 45 patients had quadriplegia, 5 had diplegia, and 1 had hemiplegia. One patient had GMFCS level I, 2 had level II, none had level III, 6 had level IV, and 42 had level $\mathrm{V}$. The mean age of the first radiographic examination of the patients was 9.4 years (2-23 years). The average age of the final investigation was 20.2 years (15-29 years). The average duration between the first radiograph and the final investigation was 10.8 years (3-19 years) (Table 1).

Figure 1 shows the development of the Cobb angle in all cases. The average final Cobb angle was $73.4^{\circ}\left(20^{\circ}-163^{\circ}\right)$. Based on the Cobb angle at the final investigation, 18, 20, and 13 patients were categorized into the $<60^{\circ}, 60^{\circ}-100^{\circ}$, and $\geq 100^{\circ}$ groups, respectively.

In 44 patients, the age at which the Cobb angle was $\geq 20^{\circ}$ was confirmed (Figure 2). The average age in the $<60^{\circ}, 60^{\circ}-$ $100^{\circ}$, and $\geq 100^{\circ}$ groups was 13.6 years, 11.3 years, and 7.6 years, respectively. The age at which the Cobb angle was $\geq 20^{\circ}$ in the $\geq 100^{\circ}$ group was significantly lower than that of the $<60^{\circ}$ and $60^{\circ}-100^{\circ}$ groups $(P=0.044$ and $P=0.044$, respectively).

Figure 3 shows the different mean values of the Cobb angle by age in the three groups. A significant difference was observed in the Cobb angle from the age of 9 years between the $<60^{\circ}$ and $\geq 100^{\circ}$ groups. From $13-19$ years, a significant difference was observed among the three groups.

Table 2 shows the factors associated with the average of the final Cobb angles, and GMFCS, capability of turning over, hip dislocation, and gastric fistula showed significant differences with respect to the final Cobb angles in the three groups.

Regarding the location and type of curve, thoracic sco-

Table 1 Patient characteristics

\begin{tabular}{ll}
\hline Male : Female (n) & $33: 18$ \\
Type of cerebral palsy (n) & Spastic 42, Dyskinetic 7, Hypotonic 2 \\
Classification of palalysis & Quadriplegia 45, Diplegia 5, Hemilplegia 1 \\
GMFCS stage (n) & I 1, II 2, III 0, IV 6, V 42 \\
Mean age at the first X-ray & $9.4(2-23)$ years of age \\
Mean age at last investigation & $20.2(15-29)$ years of age \\
Mean follow-up period & $10.8(3-19)$ years \\
\hline
\end{tabular}

$* P<0.05$ 


\section{Journal of Rural Medicine}

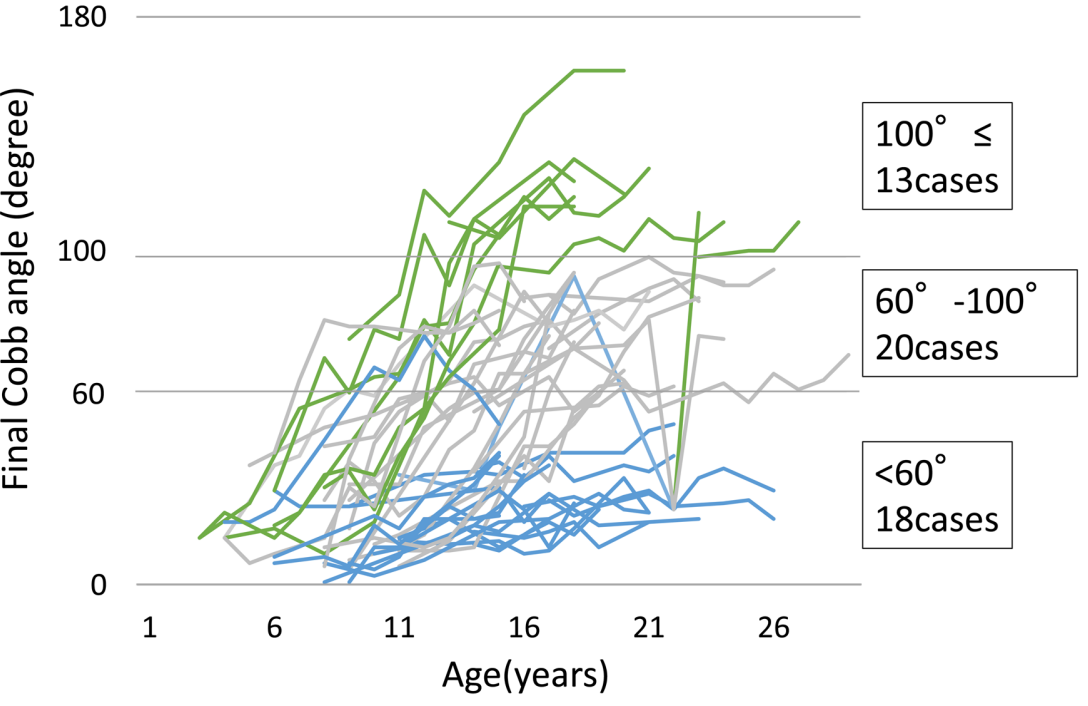

Figure 1 Development of the Cobb angle in all cases.

The average of the final Cobb angle was $73.4^{\circ}\left(20^{\circ}-163^{\circ}\right)$. Based on the Cobb angle at the final investigation, 18,20 , and 13 patients were categorized into the $<60^{\circ}, 60^{\circ}-100^{\circ}$, and $\geq 100^{\circ}$ groups, respectively.

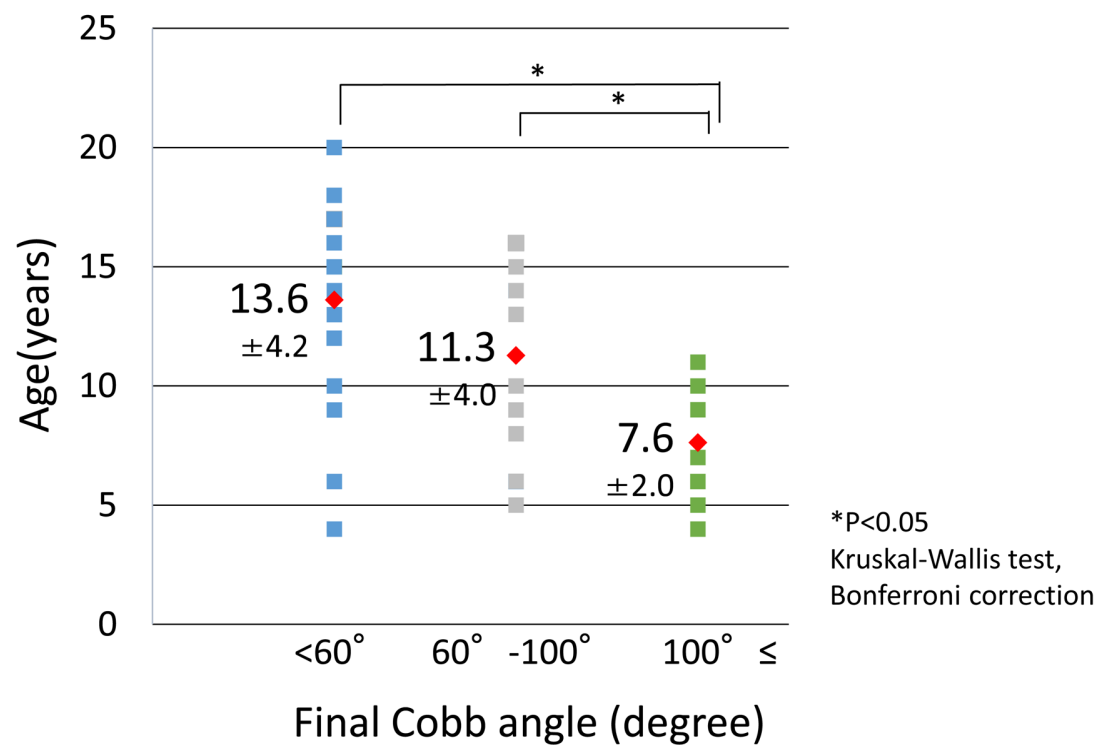

Figure 2 Detection age of Cobb angle $\geq 20^{\circ}$.

The average ages in the $<60^{\circ}, 60^{\circ}-100^{\circ}$, and $\geq 100^{\circ}$ groups were 13.6 years, 11.3 years, and 7.6 years, respectively. The age at which the Cobb angle reached $\geq 20^{\circ}$ in the $\geq 100^{\circ}$ group was significantly lower than that of the $<60^{\circ}$ and $60^{\circ}-100^{\circ}$ groups ( $P=0.044$ and $P=0.044$, respectively).

liosis was observed in 16 cases (right of the convex side in 13 cases, left of the convex side in 3 cases), thoracic lumbar scoliosis in 20 cases ( 9 in the right, 11 in the left), and lumbar scoliosis in 15 cases ( 2 in the right, 13 in the left). Thirty-three patients had a single curve, whereas 18 patients had a double curve.

A total of 42 cases were classified as GMFCS level V, whereas 9 cases were at levels I-IV. Twenty patients (9 patients with GMFCS levels I-IV, 11 with level V) were capable of turning over, whereas 31 could not. Fourteen patients wore braces, whereas 37 patients did not. The types of orthoses used were rigid under-arm brace in 2 patients and dynamic spinal brace (DSB) in 12 patients. Two patients changed from a rigid brace to a DSB. The average Cobb 


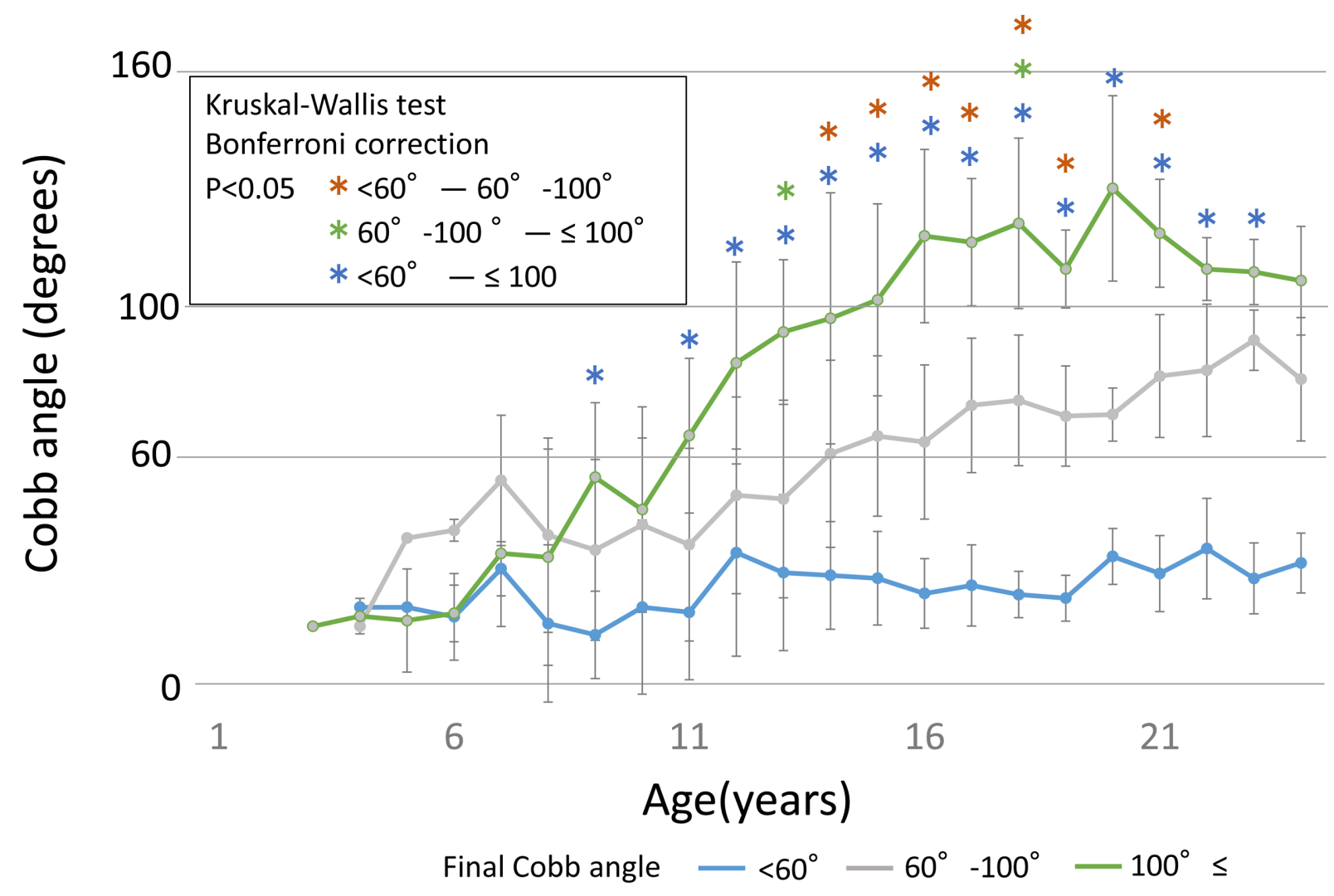

Figure 3 Mean values of the Cobb angle at different ages in the three groups.

A significant difference was observed in the Cobb angle at the age of 9 years between the $<60^{\circ}$ and $\geq 100^{\circ}$ groups. From 13-19 years, a significant difference was observed among the three groups.

angle and age at the time of starting the brace were $54.8^{\circ}$ $\left(18^{\circ}-106^{\circ}\right)$ and 14.8 years $(8.7-20.9$ years), respectively. The average duration of wearing the brace was 3.3 years (1.4-6.6 years). Nineteen patients had hip dislocation with migration percentage of $\geq 100 \%$, while 32 patients had migration percentage of $<100 \%$. Ten patients underwent tracheostomy, and 25 had gastric fistula.

\section{Discussion}

The patients with $\mathrm{CP}$ with the most severe scoliosis (Cobb angle $\geq 100^{\circ}$ ) developed the condition at a young age (average age 7.6 years), and the scoliosis progressed from 9 years of age. After the age of 13 years, the difference in Cobb angle among the $<60^{\circ}, 60^{\circ}-100^{\circ}$, and $\geq 100^{\circ}$ groups became significant, indicating that the scoliosis in these patients tended to worsen during the growth phase. This is comparable with the findings of a previous study that reported that scoliosis in $\mathrm{CP}$ is similar to adolescent idiopathic scoliosis ${ }^{3}$. During the growth phase, spasticity is enhanced by the relative shortening of the muscle length due to the rapid growth of bone, which is considered as the cause of the worsening of the scoliosis of $\mathrm{CP}$ during the growth spurt.
In addition, in severe cases of $\mathrm{CP}$, paralysis, spasticity, and imbalance of the left and right sides are intrinsically strong; thus, it is believed that scoliosis develops and progresses early. Therefore, since the early onset cases can rapidly progress to severe cases, early interventions are necessary.

In this study, the factors associated with scoliosis severity were GMFCS level V, capability of turning over, hip dislocation, and gastric fistula. There are several reports on the factors related to severe scoliosis. Previous studies reported that the risk factors of severe scoliosis were $\mathrm{GMFCS}^{7}, 8$, being bedridden ${ }^{3,4)}$, spastic quadriplegia ${ }^{4,7,9)}$, hip displacement $^{7}$, thoracolumbar curve ${ }^{3,4)}$, and early onset ${ }^{4,77}$. The risk factors for scoliosis analyzed in this study (GMFCS level V, capability of turning over, hip dislocation, gastric fistula) were associated with severe CP. The scoliosis in patients with severe motor dysfunction tends to be severe.

In our study, the final Cobb angle was significantly larger in patients with unilateral and bilateral hip dislocations. There are several reports on the relationship between hip dislocation and scoliosis, but it has not yet been clarified $\left.{ }^{7}, 10,11\right)$. Hip dislocation occurs due to the imbalance in spasticity and muscular strength of the iliopsoas, adductors, and hamstrings. Hip dislocation can lead to worse pelvic obliquity ${ }^{10)}$ 
Table 2 Factors related to severity of scoliosis

\begin{tabular}{|c|c|c|c|c|}
\hline & & Cases & Average (degree) & $P$-value \\
\hline \multirow[t]{3}{*}{ Location of the curve } & Thoracic & 16 & $73.6 \pm 41.2$ & \multirow[t]{3}{*}{0.704} \\
\hline & Thoaciclumber & 20 & $78.3 \pm 34.7$ & \\
\hline & Lumber & 15 & $66.5 \pm 37.0$ & \\
\hline \multirow[t]{2}{*}{ GMFCS } & I-IV & 9 & $24.8 \pm 6.8$ & \multirow[t]{2}{*}{$0.000 *$} \\
\hline & V & 42 & $83.8 \pm 32.0$ & \\
\hline \multirow[t]{2}{*}{ Turniug over } & Possible & 20 & $40.9 \pm 24.8$ & \multirow[t]{2}{*}{$0.000^{*}$} \\
\hline & Impossible & 31 & $94.3 \pm 27.3$ & \\
\hline \multirow[t]{2}{*}{ Orthosis } & Wearing & 14 & $72.6 \pm 21.9$ & \multirow[t]{2}{*}{0.874} \\
\hline & Not wearing & 37 & $73.6 \pm 41.6$ & \\
\hline \multirow[t]{2}{*}{ Hip dislocation } & Presence & 19 & $95.9 \pm 29.8$ & \multirow[t]{2}{*}{$0.002 *$} \\
\hline & Absence & 32 & $61.1 \pm 35.1$ & \\
\hline \multirow[t]{2}{*}{ Tracheotomy } & Presence & 10 & $91.3 \pm 40.7$ & \multirow[t]{2}{*}{0.169} \\
\hline & Absence & 41 & $69.0 \pm 35.3$ & \\
\hline \multirow[t]{2}{*}{ Gastric fistula } & Presence & 25 & $90.1 \pm 33.3$ & \multirow[t]{2}{*}{$0.001^{*}$} \\
\hline & Absence & 26 & $57.2 \pm 33.7$ & \\
\hline
\end{tabular}

$* P<0.05$

and even worse scoliosis. It is also necessary to investigate whether progression of scoliosis can be prevented by hip joint treatment.

Studies investigating the effect of using orthoses to prevent scoliosis progression are limited. Olafsson et al. ${ }^{12)}$ reported that successful treatment was observed in ambulating patients with muscle hypotonia and short thoracolumbar/lumbar curves measuring $<40^{\circ}$, as well as in non-ambulating patients with spastic short lumbar curves. Moreover, it is difficult for caregivers to assist patients with CP to wear the orthosis made of hard materials, and patients may develop redness or decubitus ulcers in the bony protrusions. Therefore, compliance with wearing orthoses is poor. Kajiura et al. ${ }^{13)}$ developed the DSB, a novel device with the basic concept of automatic correction by maximizing posture control. Nakamura et al ${ }^{14)}$ reported that DSB treatment may be effective when worn during the early stage of scoliosis. In our report, we did not find a significant difference in the final Cobb angle between patients who wore a brace and those who did not. It is important to consider that the age at which the patients started wearing the brace was 14.8 years, and the initial $\mathrm{Cobb}$ angle was $54.8^{\circ}$; thus, the time when the brace was started tended to be in the later stage of the scoliosis.

For the scoliosis of patients with CP, surgery is the definitive treatment for correcting the deformed spine and preventing its progression ${ }^{15}$. However, patients with $\mathrm{CP}$ often have complications such as respiratory disorders, gastrointestinal disorders, osteoporosis, and epilepsy; thus, spine surgery may be highly risky. In recent years, botulinum toxin injection ${ }^{16)}$ and intrathecal baclofen ${ }^{17)}$ have been used as treatment methods for controlling spasticity. Our study found that patients with early onset of scoliosis developed more severe scoliosis than those with $100^{\circ} \mathrm{Cobb}$ angle. For these cases, it is necessary to control spasticity during the early stage through methods such as internal medicine, botulinum toxin injection, and intrathecal baclofen. In addition, surgery for the scoliosis should be considered in certain cases.

The limitation of this study is that the sample size was small and the follow-up period was not sufficiently long, because this was a retrospective observational study. The scoliosis in patients with $\mathrm{CP}$ was reported to progress even after bone maturation ${ }^{4}{ }^{18}$. Thus, future studies involving a large number of patients and with a long-term follow-up duration, especially the period after bone maturation, are warranted.

\section{Conclusion}

Patients with CP with the most severe case of scoliosis, manifested as Cobb angle of $\geq 100^{\circ}$, showed scoliosis progression starting from 9 years of age. Therefore, early interventions to prevent scoliosis progression are necessary. Moreover, severe scoliosis is aggravated during the growth period, and GMFCS, capability of turning over, hip dislocation, and gastric fistula are the factors associated with scoliosis severity. Severe CP with low motor function levels and problems with internal functions was considered as the cause of deterioration of the scoliosis. 


\section{References}

1. Balmer GA, MacEwen GD. The incidence and treatment of scoliosis in cerebral palsy. J Bone Joint Surg Br 1970; 52: 134-137. [Medline] [CrossRef]

2. Madigan RR, Wallace SL. Scoliosis in the institutionalized cerebral palsy population. Spine 1981; 6: 583-590. [Medline] [CrossRef]

3. Saito N, Ebara S, Ohotsuka K, et al. Natural history of scoliosis in spastic cerebral palsy. Lancet 1998; 351: 1687-1692. [Medline] [CrossRef]

4. Majd ME, Muldowny DS, Holt RT. Natural history of scoliosis in the institutionalized adult cerebral palsy population. Spine 1997; 22: 1461-1466. [Medline] [CrossRef]

5. Bradford DS, Hu SS. Neuromusclar spinal deformity. In: Moe's Textbook of Scoliosis and other spinal deformities. 3rd ed. Lonstein JE, Winer RB, Bradford DS, et al., Eds. WB Saunders, Philadelphia, 1994; 295-322.

6. Kafer ER. Respiratory function in paralytic scoliosis. Am Rev Respir Dis 1974; 110: 450-457. [Medline]

7. Yoshida K, Kajiura I, Suzuki T, et al. Natural history of scoliosis in cerebral palsy and risk factors for progression of scoliosis. J Orthop Sci 2018; 23: 649-652. [Medline] [CrossRef]

8. Persson-Bunke M, Hägglund G, Lauge-Pedersen H, et al. Scoliosis in a total population of children with cerebral palsy. Spine 2012; 37: E708-E713. [Medline] [CrossRef]

9. Ferguson RL, Allen BL Jr. Considerations in the treatment of cerebral palsy patients with spinal deformities. Orthop Clin North Am 1988; 19: 419-425. [Medline]

10. Senaran H, Shah SA, Glutting JJ, et al. The associated effects of untreated unilateral hip dislocation in cerebral palsy scoliosis. J Pediatr Orthop 2006; 26: 769-772. [Medline] [CrossRef]

11. Porter D, Michael S, Kirkwood C. Patterns of postural deformity in non-ambulant people with cerebral palsy: what is the relationship between the direction of scoliosis, direction of pelvic obliquity, direction of windswept hip deformity and side of hip dislocation? Clin Rehabil 2007; 21: 1087-1096. [Medline] [CrossRef]

12. Olafsson Y, Saraste H, Al-Dabbagh Z. Brace treatment in neuromuscular spine deformity. J Pediatr Orthop 1999; 19: 376-379. [Medline] [CrossRef]

13. Kajiura I, Kawabata H, Okawa A, et al. Concept and treatment outcomes of dynamic spinal brace for scoliosis in cerebral palsy. J Pediatr Orthop B 2019; 28: 351-355. [Medline] [CrossRef]

14. Nakamura N, Uesugi M, Inaba Y, et al. Use of dynamic spinal brace in the management of neuromuscular scoliosis: a preliminary report. J Pediatr Orthop B 2014; 23: 291-298. [Medline] [CrossRef]

15. Cloake T, Gardner A. The management of scoliosis in children with cerebral palsy: a review. J Spine Surg 2016; 2: 299-309. [Medline] [CrossRef]

16. Nuzzo RM, Walsh S, Boucherit T, et al. Counterparalysis for treatment of paralytic scoliosis with botulinum toxin type A. Am J Orthop 1997; 26: 201-207. [Medline]

17. Eek MN, Olsson K, Lindh K, et al. Intrathecal baclofen in dyskinetic cerebral palsy: effects on function and activity. Dev Med Child Neurol 2018; 60 : 94-99. [Medline] [CrossRef]

18. Thometz JG, Simon SR. Progression of scoliosis after skeletal maturity in institutionalized adults who have cerebral palsy. J Bone Joint Surg Am 1988; 70 : 1290-1296. [Medline] [CrossRef] 